\title{
Development of Bio-artificial Pancreas using Extracellular Matrix Scaffold Technology
}

\author{
Munni Shaik ${ }^{1}$ and Subramanyam Gangapatnam ${ }^{2 *}$ \\ ${ }^{1}$ Research Faculty, Narayana Medical College, India \\ ${ }^{2}$ Research Director, Narayana Medical College, India
}

Submission: October 27, 2017; Published: December 11, 2017

*Corresponding author: Subramanyam Gangapatnam, Research Director, Narayana Medical College, India, Email: director.nmch@gmail.com

\section{Introduction}

Diabetes mellitus [DM] has reached pandemic levels and represents a growing burden both on health-care expenditures as well as the quality and quantity of life for afflicted individuals. $\beta$-cell replacement through either islet or pancreas transplantation (PTX) are the only therapies able to reliably re-establish a stable euglycemic state, long-term. Factors such as the lack of suitable donor, the burden of lifelong immune suppression, and financial issues limits the access of transplantation. Therefore identification of a new potentially inexhaustible source or method for $\beta$-cells for transplantation is extremely urgent. Among the different technologies under development, the seeding of cells on supporting scaffolding material (cell-on-scaffold seeding technology, CSST) appears to offer the quickest route to clinical application [1]. This technology is based on the striking evidence that extracellular matrix (ECM) proteins and structures play fundamental roles in the determination, differentiation, proliferation, survival, polarity, welfare and migration of cells. Various studies developed method that, through the detergent-based decellularization of porcine and human organs, allows successful and consistent production of a cellular extracellular matrix (ECM) scaffolds $[2,3]$. Cells obtained from the patient's pancreas, or induced pluripotent cells reprogrammed from patient's fibroblasts will be seeded in the 3D framework of ECM scaffolds produced from pancreata of allogenic human origin and characterized the molecular, physical, and immune properties of human pancreas acellular ECM scaffolds together with their cyto-compatibility. Literatures shows that Bio-artificial Pancreas generated from ECM scaffold technology maintain their innate molecular and spatial framework and stiffness, as well as vital growth factors.

The regenerative technologies that are currently being implemented to bioengineer pancreatic tissues for transplant purposes can be broadly classified into the following categories:

1) Islet encapsulation,

2) Biomaterial carriers, and

3) Whole-organ bioengineering.

\section{Islet Encapsulation}

Encapsulation protocols involve packaging islets within semi-permeable, bio inert membranes that selectively allow the passage of oxygen, glucose, nutrients, waste products, and insulin while preventing penetration by immune cells.

\section{Biomaterial Carriers}

The immune-related obstacles facing islet encapsulation have prompted investigators to explore regenerative technologies using auto-logous cells and bio-inert carriers. These emerging technologies employ recellularization protocols designed to seed pluripotent cells onto scaffolds capable of driving cellular proliferation and differentiation. Researchers have sought to artificially fulfill the anchorage requirement using biomaterial carriers that mimic the structure of native extracellular matrix (ECM). These carriers serve the functions of delivery platform, transitory structural support, and mechanical immune barrier, thus enabling islet transplantation into heterotopic sites [4]. Several biomaterial carriers have been investigated, including poly-lactic-coglycolicacid, poly vinyl alcohol, poly(ethylene glycol), poly(N-isopropylacrylamide), and biopolymer films [5].

\section{Pancreatic Extracellular Matrix}

The native pancreatic ECM is a 3-dimensional (3D), structural framework of proteins in a state of "dynamic reciprocity" with the cells of the endocrine pancreas [6]. The most well characterized components of the ECM are the laminins, a family of approximately 15 to 20 trimericglycoproteins [7].

\section{Decellularization-Recellularization}

ECM scaffolds from whole animal or human-cadaveric organs can be generated through detergent-based decellularization. Current decellularization techniques are capable of removing DNA, cellular material and cell surface antigens from the ECM scaffold while preserving attachment sites, structural integrity and vascular channels [8]. Decellularization protocols involve the repeated irrigation of cadaveric tissues with detergents 
or acids through the innate vasculature, although organs with higher fat content, like the pancreas, often require the addition of lipid solvents, such as alcohol [9]. Standard protocols employ a combination of ionic and nonionic detergents, enzymatic nucleases and antimicrobials, although the optimal composition and concentration of the detergent solution varies with the size, age, and density of the organ. Though previous studies reported that pancreatic decellularization may disrupt ECM protein ultra-structure [10]. Recent characterization studies of the decellularized porcine pancreas confirmed the sweeping presence of the essential structural proteins including different types of collagen, elastin, fibronectin, and laminin [11].

The decellularized, sterilized ECM serves as the scaffold on which pluripotent cells are seeded with the intent to reconstitute the cellular compartment (recellularization). Organs bioengineered from auto-logous cells may enable surgeons to successfully address the 2 major obstacles currently facing organ transplantation: (1) the need for a new, ideally inexhaustible source of organs and (2) the achievement of an immune suppression-free state post transplantation. A critical advancement in the field of organ bioengineering has been the development of suitable bioreactors. These devices allow for the continuous support, monitoring, and manipulation of the biological, biochemical, and biophysical processes involved in organ bioengineering.

\section{Whole-Pancreas Bioengineering}

Larger organs with greater parenchymal mass require higher perfusion pressures, stronger detergents and prolonged detergent exposure that may damage the native architecture and ECM proteins [3]. De Carlo et al. [11] report the successful subcutaneous implantation of PVA/PEG tubular devices containing slices of rat pancreas and liver recellularized with differentiated murine islets. Conrad et al. [12] report abbreviated findings describing the successful recellularization of murine pancreatic matrix with human islet cells and supportive MSCs. The islets showed preserved glucose-stimulated insulin response, cell viability, subcellular anatomy, and attachments.

Recently it was reported the generation of intact, wholeorgan ECM scaffolds from porcine pancreata [13]. Successful decellularization was achieved by per-fusing the innate vasculature with detergents administered via cannulas in the pancreatic duct and superior mesenteric vein. It remains unclear whether the decellularized pancreatic ECM can support the proliferation and differentiation of stem cells into the variety of cell types that compose the mature human pancreas. Even after the generation of a bioengineered pancreas has been achieved, further transplantation studies will be required to assess longterm viability, coagulation, revascularization, reinnervation, fibrosis, and potential for tumor growth.

\section{Conclusion}

These technologies rely on a robust understanding of the extracellular matrix (ECM), the supportive 3-dimensional network of proteins necessary for cellular attachment, proliferation, and differentiation. Although these functions can be partially approximated by biosynthetic carriers, novel decellularization protocols have allowed researchers to discover the advantages afforded by the native pancreatic ECM. The native ECM has proven to be an optimal platform for recellularization and whole-organ pancreas bioengineering, an exciting new field with the potential to resolve the dire shortage of transplantable organs.

\section{References}

1. Orlando G, Soker S, Stratta RJ (2013) Organ bioengineering and regeneration as the new Holy Grail of organ transplantation. Ann Surg 258(2): 221-232.

2. Mirmalek-Sani A, Orlando G, McQuilling J, Pareta R, Mack D, et al. (2013) Porcine pancreas extracellular matrix as a platform for endocrine pancreas bioengineering. Biomaterials 34(22): 5488-5495.

3. Orlando G, Farne YA, Sullivan DC, Iskandar SS, Mirmalek-Sani SH, et al. (2012) Production and implantation of renal extracellular matrix scaffolds from porcine kidneys as a platform for renal bioengineering investigations. Ann Surg 256(2): 363-370.

4. Shimizu H, Ohashi K, Utoh R, Ise K, Gotoh M, etal. (2009) Bioengineering of a functional sheet of islet cells for the treatment of diabetes mellitus. Biomaterials 30(30): 5943-5949.

5. Borg DJ, Bonifacio E (2011) The use of biomaterials in islet transplantation. Curr Diab Rep 11(5): 434-444.

6. Song JJ, Ott HC (2011) Organ engineering based on decellularized matrix scaffolds. Trends Mol Med 17(8): 424-432.

7. Otonkoski T, Banerjee M, Korsgren O, Thornell LE, Virtanen I (2008) Unique basement membrane structure of human pancreatic islets: implications for beta-cell growth and differentiation. Diabetes Obes Metab 10(4): 119-127.

8. Gilbert TW, Sellaro TL, Badylak SF (2006) Decellularization of tissues and organs. Biomaterials 27(19): 3675-3683.

9. Crapo PM, Medberry CJ, Reing JE, Tottey S, van der Merwe Y, et al. (2012) Biologic scaffolds composed of central nervous system extracellular matrix. Biomaterials 33(13): 3539-3547.

10. Tchen TT (2007) Decellularization of pancreatic extracellular matrix for a tissue-engineered pancreas. University of Pittsburgh, Pittsburgh, USA.

11. De Carlo E, Baiguera S, Conconi MT, Vigolo S, Grandi C, et al. (2010) Pancreatic acellular matrix supports islet survival and function in a synthetic tubular device: in vitro and in vivo studies. Int J Mol Med 25(2): 195-202.

12. Conrad C, Schuetz C, Clippinger B, Vacanti JP, Markmann JF, et al (2010) Bio-engineered endocrine pancreas based on decellularized pancreatic matrix and mesenchymal stem cell/islet cell coculture. J Am Coll Surg 211(3): S62.

13. Goh SK (2011) Perfusion-decellularization of pancreatic matrix-a scaffold for bio-engineered pancreas. Paper presented at: AIChE; Minneapolis, MN. 
This work is licensed under Creative Commons Attribution 4.0 Licens

DOI: 10.19080/CTBEB.2017.10.555787
Your next submission with Juniper Publishers

will reach you the below assets

- Quality Editorial service

- Swift Peer Review

- Reprints availability

- E-prints Service

- Manuscript Podcast for convenient understanding

- Global attainment for your research

- Manuscript accessibility in different formats ( Pdf, E-pub, Full Text, Audio)

- Unceasing customer service

Track the below URL for one-step submission https://juniperpublishers.com/online-submission.php 